\title{
É POSSÍVEL ESTUDAR OS FENÓMENOS MENTAIS SEM OS DESTRUIR NA SUA ESSÊNCIA? \\ UM DEBATE ENTRE FODOR E HUSSERL
}

\author{
Urbano Mestre Sidoncha
}

\section{Breve apresentação}

O estudo do tópico da consciência tem-se revelado, ao longo dos tempos, extremamente ingrato para os seus empreendedores e entusiastas. Trata-se de uma questão complexa e labiríntica, onde gravitam questões que aparentemente nada têm que ver com o problema, mas cuja omissão é um dos factores mais determinantes para a actual configuração do debate em torno da consciência. Identificar algumas lacunas que condicionam negativamente a prestação dos estudiosos, e enunciar algumas das questões adjacentes ao problema da consciência são os objectivos que nos propomos alcançar.

\section{Diagnóstico ao estado actual da discussão em torno do problema da consciência}

Um dos problemas com que somos imediatamente confrontados sempre que nos ocupamos da difícil questão da consciência é desde logo uma questão de possibilidade. Pergunta-se: é possível uma explicação última da consciência, que permita subtraí-la ao domínio do quase "indizível" em que até agora se encontra? Dir-se-á que, desde os tempos remıtos em que a questão foi por vez primeira formulada até hoje, foram feitos progressos tais que deixam antever a efectiva possibilidade de uma explicação da consciência, e até mesmo de uma explicação científica da consciência. Todavia, essa ideia de uma explicação científica da consciência exprime na verdade aquela que é uma velha reivindicação de muitos, a qual encontra na especificidade mesma dos fenómenos mentais o maior obstáculo à sua concretização. A bipolariza- 
ção que daí emerge obriga-nos a estabelecer uma espécie de ponte, por forma a que a explicação da consciência não continue a ser o tal resíduo que teima em afrontar a hegemonia das explicações científicas. O que se nota, infelizmente, é que essa compatibilização foi prosseguida, quase sempre, à custa da dissolução de um dos items em confronto, designadamente das entidades mentais. Será porventura essa a estratégia mais fácil, mas é também, como veremos, ainda insatisfatória.

Entretanto, e dado o melindre do problema, não seria de elementar prudência questionarmos a própria "legalidade" dessa pretensão da ciência em incluir no seu programa de trabalho o estudo da consciência em geral e dos fenómenos mentais em particular? Como se vê, a questão de possibilidade que antes se colocava a propósito de uma eventual compreensão da consciência converte-se agora numa questão de jure: que direito assiste à ciência para tratar de questões que aparentemente escapam ao seu domínio? Quer dizer, será legítimo esperarmos que a ciência desvende os mistérios da consciência?

Os notáveis progressos a que se assiste nas áreas mais diversas fazem crer que há, de facto, uma resposta afirmativa para a primeira questão de possibilidade. Em contrapartida, os sucessivos desaires que se verificaram nas diversas tentativas de concretizar essa possibilidade entretanto anunciada fazem com que se instale a desconfiança e o desinteresse no seio da comunidade científica. A conjugação desses factores leva muitos a duvidar da legalidade mesma dessa expansão para campos que teimam, assim, em ficar fora do domínio da ciência. Inadvertidamente, ou talvez não, o problema da consciência interrompera bruscamente o assinalável ciclo de conquistas e glórias dos cientistas, colocando com grande acuidade o problema já quase em desuso dos limites da actividade científica. São justamente essas e outras preocupações a dar o mote para o aparecimento de uma nova disciplina científica, a Ciência Cognitiva.

As Ciências Cognitivas, com apenas algumas décadas de vida, parecem efectivamente dispostas a consolidar os credos da ciência em toda a parte, mesmo nas áreas tradicionalmente adversas como o estudo e explicação da consciência. Contudo, esse desejo de tratar cientificamente as questões da consciência, animado que foi por importantes conquistas tecnológicas, não foi acompanhado do esforço necessário para compreender a natureza específica do problema em causa. Se é verdade que se fizeram progressos importantes que nos permitem conhecer cada vez melhor a consciência, não é menos verdade que se tratou de um avanço rectilíneo, feito num único sentido, quando a dimensão do problema exigiria uma abordagem mais ampla. No entanto, o problema maior não é sequer este: mais grave do que conhecer apenas alguns aspectos relativos à consciência, é pretender que esse conhecimento representa a totalidade das determinações que caracterizam a nossa vida mental. 
Se quisermos recuar mais um pouco neste processo que toma a parte pelo todo, é possível apurar com relativa facilidade a origem deste equívoco. $\mathrm{O}$ diagnóstico do problema encontrou, aliás, em David Chalmers ${ }^{1}$ uma das formulações mais claras que se conhecem. Como bem observou Chalmers, até agora temo-nos debruçado sobre as questões acessórias do problema da consciência, as quais, sendo importantes, não colhem a verdadeira natureza da questão. É justamente isso que o autor pretende enfatizar com a sua bem conhecida distinção entre easy e hard problems. Os aspectos fenomenais associados às nossas experiências não cabem no âmbito de uma simples abordagem fisicalista ou funcional da consciência. Não que se trate de uma análise despropositada, incapaz de colher aspectos importantes da nossa vida psíquica. Como bem notou Chalmers, estas abordagens são necessárias desde que não se assumam como teorias exclusivas de tais fenómenos. É importante conhecer esses mecanismos, na certeza que esse conhecimento nos permite uma aproximação cada vez mais efectiva à verdadeira essência da nossa consciência. Mas esse é apenas uma pequena parte do trabalho a desenvolver, porventura a parte mais fácil (para utilizar a sugestão de Chalmers), mais desassombrada, que encontra aliás correspondência nas recentes conquistas feitas principalmente ao nível das ciências neurológicas.

A questão que no fundo se coloca, e cuja resposta divide as comunidades científica e filosófica, é saber se a consciência é apenas o seu substrato material, quer dizer, se o conjunto da vida psíquica se esgota nesse complexo processo de correlatos neuronais ${ }^{2}$. Ora, a menos que se queira deliberadamente sacrificar esse lado fenomenal da nossa vida mental, a resposta só pode ser manifestamente negativa. Isto permite-nos concluir sem hesitações que toda a estratégia desenvolvida sob a égide das Ciências Cognitivas para a compreensão da consciência falha claramente na prossecução daquele que era o seu objectivo fundamental.

Todavia, e atendendo ao malogro destas tentativas, tornava-se necessário e urgente engendrar novas estratégias que permitissem colmatar a ausência de soluções para o estudo da consciência. E, apesar de ainda não estar rigorosamente definida, essa nova tentativa tem já o seu objectivo delineado, o qual é no mínimo ambicioso: deve ser capaz de acalentar a ideia de uma explicação científica dos fenómenos mentais ao mesmo tempo que se mostra empenhado na restituição da natureza intrínseca desses mesmos fenómenos. Tratam-se de exigências que até agora se tinham revelado contraditórias, uma vez que os teóricos que se ocuparam do problema foram, de facto, incapazes de harmonizar esses simples preceitos. Efectivamente, dualistas e ma-

${ }^{1}$ Chalmers, David J, The Conscious Mind - In Search of a Fundamental Theory, New York/ Oxford, Oxford University Press, 1996.

${ }^{2}$ A respeito deste confronto entre as comunidades filosófica e científica em torno do tópico da consciência, $C f_{\text {. }}$ CHANGEUX, Jean-Pierre, RICOEUR, Paul, O Que Nos Faz Pensar, Lisboa, Edições 70, 1998. 
terialistas, por vias naturalmente distintas, procuraram "forçar" os fenómenos mentais a aderir a uma estrutura conceptual previamente delineada. $\mathrm{O}$ prejuízo daí resultante era evidente: o ajustamento coercivo dos fenómenos mentais a essas estruturas explicativas implicava o sacrifício de aspectos essenciais da nossa vida mental em nome da coerência interna dessas teorias.

Como se consegue então operar a compatibilização entre a exigência de uma teoria científica para a consciência e a exigência aparentemente contrária de defesa da natureza dos fenómenos mentais, designadamente na sua dimensão fenomenal?

\section{Do que é que é necessário defender os fenómenos mentais?}

Antes, porém, de aflorarmos em mais detalhe os contornos que uma solução coerente deve necessariamente apresentar, cabe-nos explicar o que é se pretende exactamente quando se fala do desrespeito pela natureza dos fenómenos mentais ou quando falamos ainda da necessidade de "salvar" os fenómenos mentais, por forma a avaliarmos com todo o rigor a dimensão do problema em causa. Para o efeito, nada melhor do que rever uma dessas teorias que não soube ou não pôde preservar a compleição dos fenómenos mentais. Isto permite-nos, por um lado, avaliar o impacto negativo que resulta da integração coerciva dos fenómenos mentais em determinadas estruturas explicativas, mas também, por outro lado, fazer um levantamento das circunstâncias necessárias para uma efectiva restituição dos fenómenos mentais e, com elas, para um melhor conhecimento da consciência e dos seus fenómenos.

São dois os interlocutores intervenientes nesta discussão. De um lado, encontramos Jerry Fodor, que é um exemplo elucidativo daquilo que é a incapacidade em preservar a natureza dos fenómenos mentais; do outro temos Husserl, que pelo contrário surge como representante legítimo dos que protagonizam a defesa intransigente dos fenómenos mentais. Como teremos ocasião de ver, o confronto de ideias que subjaz a esse debate deixará claro que a explicação dos fenómenos mentais tem a dignidade de se constituir, por si só, em objecto de investigação. Isto significa que a nossa vida mental não pode ser subordinada (leia-se, "estar ao serviço de") a um qualquer outro objectivo, por mais importante que ele possa ser.

Fodor estará na origem de uma daquelas situações que assinalámos atrás como constituindo um embaraço ao apuramento eficaz da essência dos fenómenos mentais. A razão é simples: a sua reconstrução representacional da intencionalidade revelar-se-á perfeitamente desajustada relativamente àquilo que já se conhece dos fenómenos mentais, e muito em particular, face àquilo que se conhece da natureza específica dos fenómenos mentais intencionais. Como tal, em vez de contribuir positivamente para um conhecimento cada vez mais efectivo em relação à consciência e aos seus fenómenos, 
traduz-se ao contrário num considerável desvio face a esse mesmo objectivo. Mas para termos uma noção mais exacta da extensão desse desvio e de suas implicações, importa que nos detenhamos mais demoradamente sobre o quadro teorético que envolve e justifica as posições assumidas por Fodor.

Para a prossecução dos seus objectivos, Fodor sentiu que era necessário propor a naturalização dos fenómenos mentais, designadamente daqueles que possuem a propriedade da intencionalidade. O que é que isto significa? Segundo o representacionalismo contemporâneo (movimento em que Fodor se inscreve), a representação mental é um símbolo. Isto faz com que qualquer tentativa de naturalizar a explicação intencional em termos representacionais implique, no mesmo passo, uma conversão em termos simbólicos. Ora, será justamente esta identidade entre representação e símbolo a criar os maiores embaraços à tentativa de naturalização via representacionalismo. Como veremos, apesar de se revelar consentâneo com os objectivos filosóficos preconizados por Fodor, a reconversão em termos representacionais (e portanto em termos simbólicos, atendendo à identidade entre representação e símbolo que já tivemos ocasião de destacar) dos fenómenos intencionais revelar-se-á perfeitamente desajustada e distante face à verdadeira essência dos fenómenos mentais. Isto não significa no entanto que as noções de "representação" e "símbolo" estejam definitivamente condenadas à separação. O próprio Husserl, que aqui chamaremos à colação para tentar clarificar a natureza dos fenómenos mentais, serve-se deste expediente que consiste em associar estas noções aparentemente desavindas.

Entretanto, a grande "obsessão" de Fodor, ou melhor, o objectivo que perseguia incessantemente nesta fase era o de conseguir para a teoria psicológica o estatuto de ciência. No entanto, a prossecução desse objectivo fazia pressupor a observância de alguns preceitos que o próprio Fodor identifica. Desde logo, era necessário garantir uma eficácia explicativa aos elementos mentais, mais concretamente, aos que dispunham do atributo da intencionalidade. Mais, era necessário que essa eficácia explicativa recaísse sobre os conteúdos intencionais desses elementos mentais. O objectivo último era o de conseguir transformar uma forma específica de explicação psicológica, que o autor designa de Realismo Intencional, numa sequência causal de estados intencionais. No entanto, a tentativa de trazer para o âmbito da psicologia a tal determinação de ciência implica o cumprimento de outra exigência fundamental: segundo essa exigência suplementar, as propriedades mentais, que são de facto os princípios essenciais do Realismo Intencional, só são cientificamente aceitáveis se e somente se as pudermos transformar em propriedades naturais, o mesmo é dizer, em propriedades afins àquelas que são admitidas pelas ciências físicas. Dito de outra forma, a reivindicação do estatuto de ciência para uma dada forma de explicação psicológica implicava a naturalização das propriedades mentais. Tratava-se, todavia, de um requisito com elevado grau de exigência: a explicação psicológica, que re- 
clamava eficácia causal para os estados intencionais, exige agora que esses estados sejam naturalizados, i.e., que de alguma forma se convertam em processo físico. Mas, atendendo ao facto de essa conversão não poder ser feita por uma identificação tout court, visto que o próprio Fodor subscreve a tese que atesta o fracasso do reducionismo moderno, ficamos sem saber exactamente que espécie de conversão naturalista pretende o autor para os fenómenos mentais.

Mas apesar de se mostrar hesitante em algumas ocasiões, cremos ser possível traçar em linhas gerais o tipo de naturalização que Fodor tinha em mente. Em defesa da sua tese da naturalização dos estados mentais, Fodor adianta que a naturalização do elemento intencional implica a sua conversão em termos representacionais/simbólicos. De salientar que é o próprio Fodor quem define esta medida como uma medida reducionista sensu stricto (na medida em que reduz estados intencionais a representações mentais), considerando ainda que ela faz parte de uma estratégia mais ampla a que chama "redução dupla"

A primeira fase desta estratégia resulta da simples constatação de uma semelhança: os símbolos (designadamente, os símbolos linguísticos) são as únicas entidades que, além dos estados intencionais, têm simultaneamente propriedades causais e propriedades semânticas (i.e., a propriedade de ser acerca de). Ora, dada a existência deste paralelismo que parece ser demasiado forte para se tratar de uma mera coincidência, é possível reduzir essas duas propriedades a uma única propriedade. A segunda etapa consiste, assim, na instituição de uma relação de identidade parcial e de derivação entre a intencionalidade do estado mental e a capacidade representacional de uma representação mental (imediatamente definidas como símbolos mentais dotados da mesma natureza dos símbolos linguísticos). Uma vez concretizada esta segunda fase da redução, a intencionalidade do estado mental não será mais do que a intencionalidade da representação mental. Mais, é agora a representação mental quem tem, em primeiro lugar, essa propriedade semântica (de ser acerca de), tendo tudo o resto que é intencional herdado a sua intencionalidade das próprias representações mentais. Com isso, a representação mental ganha o estatuto de componente essencial do próprio estado intencional.

É fácil avaliar as consequências destas duas fases que integram a estratégia da redução dupla: uma concepção semântica da intencionalidade, o mesmo é dizer, a identificação parcial (e portanto, a derivação) da intencionalidade mental com as propriedades semânticas de uma representação mental. Tudo isto dá origem a uma imagem simbólica do realismo intencional, que é de resto o sentido mesmo da reconstrução representacional do in-

${ }^{3}$ Cf. A este respeito Mental Representation: an Inroduction. 
tencionalismo. Podemos abreviar os termos em que essa reconstrução se processa, e que dá origem à tal concepção semântica da intencionalidade

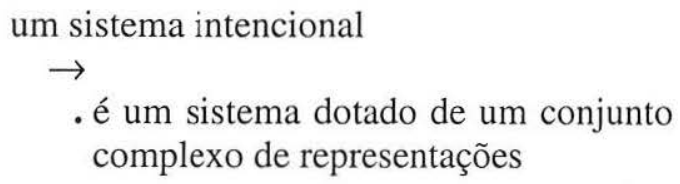

- tem a propriedade semântica de ser acerca de um objecto exterior, tal como o símbolo linguístico tem a propriedade semântica de ser acerca daquilo de que é símbolo

Mas uma concepção desta natureza apresenta naturalmente as suas limitações. Aquela que nos parece mais flagrante prende-se justamente com o problema de saber se a tal reconstrução representacional da intencionalidade que lhe deu origem é ou não adequada aos fenómenos intencionais.

\section{Ter-se-á afastado o fodorismo da compreensão dos fenómenos mentais?}

Notemos que a solução deste problema está longe de ser linear. Primeiro é necessário explorar a própria noção de fenómeno intencional tal como Fodor a concebeu. Ao fazê-lo, veremos que, no âmbito das suas investigações, "fenómeno intencional" se refere claramente à psicologia de senso comum (leia-se, ao sistema conceptual que se refere a estados intencionais não-lógicos, como os dados comportamentais ou os dados de primeira-pessoa). Ora, aquilo que Fodor pretendia com a sua reconstrução do intencionalismo e, portanto, com uma concepção simbólica da intencionalidade, era precisamente encontrar um substituto para esse sistema conceptual da psicologia de senso-comum, de preferência por um que obedecesse às exigências de cientificidade. Visto assim globalmente o projecto de Fodor, é possível aperfeiçoar a questão que colocámos atrás. Eis então a nova configuração do problema: a reconstrução representacionalista do intencionalismo, a concepção semântica da intencionalidade dela resultante e, portanto, a mudança entre sistemas conceptuais (da psicologia de senso comum para uma versão naturalizada desse sistema) preenche ou não o requisito de se adequar aos fenómenos intencionais? A resposta é claramente não.

Desde logo, porque não faz justiça a dois tipos cruciais de fenómenos intencionais. A reconstrução representacionalista do intencionalismo transforma toda a relação intencional com um objecto numa relação simbólica, 
excluindo assim a possibilidade de introduzir uma distinção, também ela fundamental, entre estados intencionais simbólicos e estados intencionais não-simbólicos. Essa omissão é tão mais perniciosa quanto maior é a nossa percepção da sua clareza e irrefutabilidade: uma coisa é um estado mental relacionar-se com um objecto por intermédio de um símbolo, e outra inteiramente distinta é relacionar-se com esse objecto sem qualquer mediação simbólica. Como sair então deste impasse ${ }^{4}$ ?

Uma possibilidade passaria pela rejeição de uma das acepções mais comuns de símbolo, pela qual se diz que símbolo é "algo que está no lugar de qualquer outra coisa", ou de uma forma mais abreviada, um substituto. Mas para se tratar de um substituto, além da capacidade de se referir a outro objecto para lá de si mesmo, o símbolo deve poder ainda ser um elemento intermediário que torna a relação com qualquer outra coisa possível. E é justamente desta última definição subsidiária da noção de "símbolo" que Fodor parece ter-se esquecido: o símbolo pressupõe um elemento $x$ como fonte da relação simbólica e, enquanto tal, desempenha ele mesmo o papel de uma entidade intermediária. Como conciliar então esta ideia com aquela outra, que constitui também ele um dado fenomenológico óbvio, segundo a qual alguns dos nossos estados mentais são intuitivos (portanto, não simbólicos)? Como se vê, permanecemos no impasse de há pouco.

Outra possibilidade seria optar por uma versão do Realismo Intencional que excluísse todos os estados intencionais deste tipo não-simbólico. No entanto, são muitos os problemas que se associam a este tipo de solução: o primeiro, e que nos parece óbvio, é que se trata de um simulacro de solução, porquanto o problema é resolvido pela dissolução do próprio problema. Não fazendo referência aos estados intencionais intuitivos, a generalização da estrutura simbólica torna-se aparentemente uma medida adequada e de fácil execução. Além disso, esta posição viola claramente a apreensão mais imediata dos fenómenos intencionais. Porém, ainda que admitíssemos que a intuição é efectivamente uma ficção, ficariam mesmo assim excluídos outros tipos de estados intencionais que justamente não se enquadram na estrutura simbólica da intencionalidade. Pode então concluir-se sem a menor hesitação que a definição simbólica de estados intencionais, resultante desta estratégia da redução dupla, faz com que seja necessário tratar a intencionalidade como uma relação com um objecto sempre mediada por um substituto para esse objecto. Ao fazê-lo, a definição simbólica da intencionalidade não permite acomodar a distinção importantíssima entre intencionalidade simbólica

${ }^{4}$ Com efeito, gerou-se uma situação dilémica que urge ser resolvida. Ao considerar que toda a relação intencional, por ter uma estrutura simbólica, é uma relação indirecta, estamos seguramente a desrespeitar a natureza dos fenómenos intencionais, visto que há um número significativo desses fenómenos que não se revêm nesta apreciação aparentemente genérica acerca da essência do intencionalismo. 
e não simbólica, bem como o carácter directo de inúmeros estados intencionais.

Como vemos, uma naturalização apressada dos estados mentais leva a que se cheguem precisamente àquelas situações que denunciámos como estando na origem de uma compreensão equívoca da nossa vida mental. A estratégia delineada por Fodor, em vez de retratar com rigor a natureza dos nossos estados mentais, cria antes uma visão distorcida e distante daquela que é a verdadeira essência do mental. A razão dessa clivagem é simples: a compreensão escrupulosa dos fenómenos mentais assume para Fodor um carácter episódico face àquele que é o seu objectivo fundamental, e que se prende justamente com a necessidade de reconstruir a psicologia de senso comum em termos representacionais.

Pelo que até agora se disse, pode concluir-se imediatamente que o intento de Fodor está irreversivelmente de costas voltadas para a essência dos fenómenos mentais. Todavia, essa conclusão deve ser ainda criteriosamente analisada. Por isso mesmo, a questão que não podemos deixar de nos colocar é a de saber se é ou não possível reconciliar esta versão representacionalista do realismo intencional com os próprios fenómenos intencionais. Quer dizer, pretende-se apurar se a naturalização dos fenómenos intencionais prevista no programa de reconstrução representacionalista é ou não consentânea com a natureza dos próprios fenómenos mentais. Isso coloca-nos perante questões muito delicadas. Desde logo, falámos de naturalização dos fenómenos mentais. Será que a naturalização que nos propôs Fodor é a mesma de que hoje se fala quando se aponta para a naturalização da fenomenologia como solução para a abordagem das questões de filosofia da mente? Além disso, qual a importância das teses husserlianas no quadro desta tentativa de compatibilização entre fenómenos mentais e a reconstrução representacionalista da intencionalidade, tendo em conta que Husserl sempre se opôs à naturalização da consciência? Finalmente, estão ou não criadas as condições que nos permitam asseverar, com propriedade, que doravante serão respeitados os fenómenos mentais, independentemente dos interesses de circunstância desta ou daquela teoria explicativa?

\section{A fenomenologia husserliana como uma nova forma de abordar os fenómenos mentais - a luta contra a naturalização da consciência}

Comecemos por Husserl. A razão que nos leva aqui a dar uma atenção especial a Husserl prende-se com a própria natureza do problema que temos entre mãos.

Denunciámos a forma de certo modo "ligeira" como até agora se tem olhado para o estudo dos fenómenos mentais, e vimos que a versão representacionalista do realismo intencional de Fodor não contribuía muito para reverter a situação. Era necessário uma nova forma de olhar para os fenóme- 
nos mentais, e a fenomenologia husserliana oferece-nos justamente essa possibilidade. Ao garantir uma descrição tão rigorosa quanto possível dos fenómenos intencionais, Husserl afasta decididamente o espectro das teorias que, ao forçarem os fenómenos a integrar uma estrutura (no caso) simbólico-representacional, se revelam totalmente desajustadas. Ora, se é verdade que a análise husserliana traz benefícios claros para uma análise rigorosa dos fenómenos mentais, não é menos verdade que esse contributo passa a ser controverso quando se trata de harmonizar essa análise de rigor com uma estratégia que quer naturalizar a explicação intencional. Como sabemos, um dos traços mais conhecidos da fenomenologia husserliana é precisamente a sua divergência em relação às ciências naturais. São várias as motivações que fizeram da luta contra a naturalização da consciência uma das maiores preocupações de Husserl.

Em primeiro lugar, Husserl considerava que era necessário subtrair a consciência ao campo das ciências positivas, cujos procedimentos eram impróprios para determinar aquilo que é próprio e exclusivo da vida mental. $\mathrm{O}$ autor mostrou habilmente que a consciência tem uma estrutura intencional, e portanto ideal, que faz com que ela seja irredutível aos procedimentos das ciências positivas ou experimentais. Por outras palavras, a essência intencional da consciência e dos seus actos impedia que a sua actividade fosse reduzida a um conjunto de factos empíricos.

Nas suas Investigações Lógicas, Husserl desenvolve precisamente a ideia de que o estudo dos actos de consciência deve ser qualquer coisa diferente das abordagens tradicionais da psicologia empírica. As exigências metodológicas dessa disciplina obrigavam que as nossas vivências fossem vistas na sua mera facticidade ou efectividade, como um campo positivo de objectos entre os demais. Os seus resultados eram, nesse sentido, solidários com os das restantes ciências positivas. No entanto, no período das Investigações Lógicas não havia ainda a ideia nítida de que esse estudo da consciência podia ser substancialmente diverso de uma psicologia. Husserl refere-se ainda a esta nova disciplina como uma psicologia descritiva. De qualquer forma, estavam já definidos os objectivos fundamentais da futura fenomenologia: um estudo reflexivo da consciência que permita surpreender de uma forma permanente a sua actividade. Estamos assim longe daquela perspectiva segundo a qual a consciência é ainda entendida como um olhar puro, destituído de qualquer forma ou estrutura, que se limita simplesmente a revelar ou representar a especificidade dos objectos de que se tem consciência, e que portanto só ganha formas determinadas pela impressão dos objectos que surgem diante de si; é a imagem paradigmática da consciência como tábua rasa. Segundo nos dirá Husserl, a estrutura intencional da consciência determina esse algo de que (só por essa via) temos consciência, o que representa a assunção definitiva de uma nova atitude perante as questões da consciência. 
Como se vê, a fenomenologia investiga uma região do ser que não é natural, porquanto é uma região que é composta por essências, as essências das vivências puras (puras no sentido em que estão abstraídas das suas conexões com a realidade natural). Mais, a forma descritiva desta nova disciplina (já sublinhada nas Investigações Lógicas) difere substancialmente da forma nomológica própria das ciências dos objectos naturais. Isso prende-se aliás com outra questão decisiva, que se reporta aos limites próprios da ciência do tempo de Husserl, que faziam da ideia de uma física da fenomenalidade uma ideia autocontraditória nos termos mesmos em que se apresenta. Uma eidética descritiva geométrica era um projecto impossível de concretizar, não por razões menores mas por questões de fundo, que se prendem com a própria natureza da axiomatização.

Como vemos, são muitos os indícios que nos permitem concluir pela incompatibilidade entre naturalização e uma descrição rigorosa dos fenómenos mentais. Diante disto, a tentativa de homogeneizar a estratégia fodoriana que recorre à naturalização das propriedades mentais com a ideia de uma abordagem capaz para as questões de consciência ganha um inesperado interesse.

Que Husserl seja um interlocutor privilegiado para uma tentativa de resgatar os fenómenos intencionais não é surpresa, tendo em conta aquilo que se disse acerca da fenomenologia husserliana. Mas são essas mesmas considerações que tornam estranha a tentativa de reconciliar a versão representacionalista do realismo intencional (a tal que naturaliza a explicação intencional) com a tal descrição de rigor dos fenómenos mentais que pretende a fenomenologia husserliana.

Analisemos então paulatinamente as razões que nos levam a recorrer à fenomenologia de Husserl.

\section{A "naturalização" dos fenómenos mentais, a sua reconstrução representacional, pode afinal ser consentânea com a essência do mental?}

Ao contrário do que se verificava na proposta de Fodor, a teoria da intencionalidade de Husserl garante imediatamente um papel chave à distinção entre estados intencionais simbólicos e não simbólicos, e fá-lo dispondo-a como uma oposição entre um tipo directo e indirecto de intencionalidade. Perante isso, falta ver se o conteúdo da análise husserliana relativamente aos estados intencionais oferece então uma saída para as dificuldades do fodorismo, e se o faz reconciliando a concepção simbólica de representação mental com a tal distinção entre estados intencionais simbólicos e não-simbólicos ou se, pelo contrário, o faz renunciando à assimilação entre as noções de símbolo e representação, optando assim por uma versão não simbólica do representacionalismo. 
Aquilo que podemos asseverar desde já é que a teoria da intencionalidade (ou análise das estruturas gerais da intencionalidade) desenvolvida na II. ${ }^{a}$ edição das Logische Untersuchungen constitui efectivamente uma forma de representacionalismo. É isso que diz o próprio Husserl no início da quinta investigação lógica, onde justamente conduz a análise das estruturas gerais da intencionalidade sob a forma de um criticismo da teoria proposta por Brentano em Psicologia de um Ponto de Vista Empírico. No capítulo $3^{\circ}$ dessa mesma investigação quinta, Husserl critica abertamente a tese segundo a qual cada estado intencional é ou uma representação ou tem uma representação como sua base necessária. Note-se contudo que Husserl rejeita não o princípio per se, mas apenas a interpretação que Brentano dele faz. Husserl considera que o termo representação (como quase todos os outros da psicologia descritiva) estava carregado de vários sentidos, pelo que se impunha uma clarificação sistemática. Essa complicada tarefa de clarificação é efectivamente feita, e dela resulta a identificação de inúmeros sentidos, que podem ser divididos em duas grandes categorias. Num primeiro sentido do termo, a representação (Vorstellung) não é nada mais do que aquilo a que Husserl chama a matéria de um acto. Depois de defender, contra Brentano, a ideia da transcendência do objecto intencional, e de ter feito a distinção, no âmbito do próprio estado (Erlebnis) intencional, entre uma parte intencional (ideal, a noesis na terminologia de Ideen) e outra não intencional (a hyle), Husserl separa agora o próprio acto intencional em dois componentes: a Matéria (Materie) e a Qualidade (Quälitat). A matéria de um acto é definida como o elemento responsável por estabelecer a relação intencional com um objecto. Mas, dir-se-á, qual é nesse caso o objectivo desta distinção, sendo, como de facto é, a matéria condição suficiente para estabelecer a relação intencional com o objecto? A exigência a que o autor pretende dar resposta com a distinção entre matéria e qualidade do acto é a de enfatizar a ideia de que a intencionalidade só existe modalizando-se, (quer dizer, assumindo uma qualidade posicional como por exemplo a crença) isto é, de que a consciência e toda a actividade consciente, enquanto intencional, só poderá existir como modo determinado de relação ao objecto.

Ora, se a matéria é parte integrante de cada acto/vivência, e se um acto está incluído (ou mais do que isso, é) em cada estado intencional, segue-se que todos os estados intencionais são para Husserl claramente representacionais neste primeiro sentido de representação.

Deste primeiro conceito de representação, Husserl faz derivar um segundo conceito (cuja explicitação cabal é consumada apenas na sexta investigação lógica), para o qual reserva a palavra Repräsentation (usarei ocasionalmente a abreviação Rtn). A Rtn designa a conjunção da matéria de um acto com a parte não-intencional do estado intencional (que Husserl também designa de "conteúdo representacional"). Como veremos, este segundo con- 
ceito revelar-se-á decisivo para o desenvolvimento ulterior das posições filosóficas do autor.

Entretanto, há outro aspecto seguro acerca da teoria husserliana da intencionalidade que devemos assinalar: trata-se do facto de ela estar sustentada numa clivagem fundamental entre estados intencionais simbólicos e intuitivos (algo que, como se viu, era impossível de alcançar no fodorismo). Na primeira investigação lógica, que Husserl dedica à descrição da intencionalidade simbólica ${ }^{5}$ (considerada um tipo específico de intencionalidade), o objectivo manifesto não é o de inquirir sobre a natureza geral dessa intencionalidade simbólica, mas apenas sobre as suas espécies mais importantes do ponto de vista da lógica, como é o caso da intencionalidade linguística ou expressiva. Isto significa também que, nesta primeira investigação, vão ser apresentadas as características que uma relação intencional deve apresentar para ser simbólica. Como é então anunciada a intencionalidade linguística?

A intencionalidade linguística ou expressiva (porque justamente faz uso de uma expressão linguística, Ausdruck) é descrita como um estado intencional complexo, composto por dois estados mais simples também intencionais que têm como correlato intencional uma entidade mais complexa, mas em que $o$ referente é apreendido como o mais importante. A especificidade desta intencionalidade linguística é a sua indireccionalidade: intuímos um "objecto" (no caso, uma expressão linguística escrita ou falada) por forma a chegar a outro (o referente da expressão), sendo a única função do primeiro tão-só a de ser um substituto para o segundo ${ }^{6}$.

Ora, esta análise é suficientemente genérica para que facilmente possa ser extensível a todas as formas simbólicas de intencionalidade (visto que a intencionalidade linguística é apenas uma das espécies da intencionalidade simbólica), podendo assumir-se assim como a verdadeira essência deste tipo de intencionalidade. Mas, uma vez que a relação intencional simbólica com um objecto é estabelecida por intermédio de um substituto, essa relação é também para Husserl uma relação com algo que está ausente para o sujeito ${ }^{7}$ : aquilo que está presente é o substituto do objecto, não o próprio objecto ${ }^{8}$.

Como se esperava, estas considerações produzem naturalmente os seus efeitos. E a consequência directa é o facto de a primeira definição de intencionalidade simbólica implicar que cada estado intencional expressivo (lin-

5 O tema da Investigação é justamente "Ausdruck und Bedeutung"

${ }^{6}$ A intuição do símbolo é nestes casos absolutamente indispensável para que nos possamos relacionar intencionalmente com o referente do símbolo, que é exactamente aquilo com que queremos estar intencionalmente relacionados.

${ }^{7}$ A não ser que o objecto seja apreendido intuitivamente num acto adicional, mas então é de outra coisa que estamos a falar.

${ }^{8}$ Ao contrário, a essência da relação intencional intuitiva é ser directa, e, nesse sentido, pode ser entendida como um contacto com o próprio objecto, que está assim presente para o sujeito. 
guístico) seja necessariamente um acto complexo, baseado na intuição de um objecto que desempenha o papel de um substituto. No entanto, esta definição seria rapidamente contestada nos desenvolvimentos ulteriores das Investigações. Na quinta investigação lógica, Husserl introduz uma curiosa nota de contradição, quando considera que a expressão linguística escrita ou falada é "dispensável"9. Mas, como pode o símbolo (a tal entidade intermediária ou substituto) desaparecer sendo, como de facto é, essencial para que uma relação intencional simbólica possa depender da mediação de um outro objecto? A única hipótese plausível para sanear este conflito interno nas posições de Husserl é admitir que a primeira investigação lógica falha claramente em revelar a essência genérica da intencionalidade simbólica.

Isto não significa que Husserl tenha hipotecado a tese segundo a qual a indireccionalidade é a marca da relação intencional simbólica, mas apenas que essa indireccionalidade deve ser situada a um nível mais profundo do estado intencional. Essa é de resto a direcção que o autor deu às suas duas últimas investigações, onde justamente procura definir a oposição entre intencionalidade simbólica e intuitiva como uma diferença de Repräsentation ${ }^{10}$ (o tal segundo sentido do termo "representação", que define a conjunção da matéria de um acto com a parte não-intuitiva do estado intencional, i.e., com o conteúdo representativo).

De facto, a matéria e o conteúdo representativo de um acto têm papéis bem distintos. A primeira constitui o próprio coração do estado intencional; é aquilo que torna possível a relação intencional. O segundo, por sua vez, é incapaz de, por si só, se referir ao que quer que seja; a matéria do acto precisa aparentemente da sua mediação por forma a poder relacionar-se intencionalmente com o objecto. Por outras palavras, numa Repräsentation ${ }^{11}$ a matéria do acto estabelece uma relação intencional através de um conteúdo representativo $^{12}$. Ora, a verificar-se esta relação, a Rtn oferecerá no seu nível mais genérico o mesmo tipo de indireccionalidade que, segundo a análise da primeira investigação lógica, era suposto captar a especificidade do tipo simbólico de intencionalidade. Por outras palavras, algo da essência da intencionalidade simbólica, tal como nos foi apresentada na primeira investigação,

${ }^{9}$ Cf. $\S 19$ V IL.

${ }^{10}$ Note-se que atrás havíamos já prevenido para a importância desta segunda acepção do termo representação. Como veremos, é sobre esta Repräsentation que recai a responasbilidade de obviar as grandes dificuldades que se colocam no âmbito da descrição das estruturas gerais da intencionalidade.

11 Aquilo que, no dizer de Brentano, cada estado intencional é, ou ainda que constitui a sua base necessária. Tivemos oportunidade de ver justamente que este é um dos sentidos que o termo "representação" acolhe, e é a partir dele que Husserl vai desenvolver grande parte da sua argumentação subsequente.

12 Nesta fase (Cf. $\$ 14$ da quinta $I L)$, Husserl descreve explicitamente a relação entre a matéria e conteúdo representativo em termos de interpretação (Deutung). 
parece pertencer de facto a todos os estados intencionais, tanto quanto cada estado intencional é agora concebido como uma relação com uma entidade mediada por outra. É que a matéria do acto está efectivamente em relação com o conteúdo representativo, mas está assim relacionada de modo a ser capaz de alcançar o próprio objecto intencional.

Perante este desenvolvimento surpreendente da análise husserliana, um leitor mais desatento pode concluir apressadamente que a assimilação da estrutura genérica da Repräsentation com a da intencionalidade simbólica, nos termos em que aparece descrita na primeira investigação lógica, não é fiel ao pensamento de Husserl, e que resultaria na verdade de uma interpretação abusiva quanto ao uso de termos similares em contextos diferentes. $\mathrm{O}$ que devemos então fazer é devolver a palavra ao próprio Husserl, para ver se esta conclusão é ou não consentânea com a sua própria análise. E o que podemos constatar quase imediatamente é que o próprio Husserl assume esta assimilação, exprimindo-a num dos momentos cruciais da quinta investigação lógica. Note-se, no entanto, que em nenhum momento Husserl assevera que a Rtn é idêntica a uma intenção significativa quando acompanhada pela expressão correspondente, mas sim que entre elas é possivel introduzir uma analogia, quer dizer, uma identidade na diferença. Vejamos então em esquema a apresentação desta relação que entretanto se estabeleceu:

$\begin{array}{llcl}\text { Matéria } & \rightarrow & \begin{array}{c}\text { Símbolo/Substituto } \\ \text { Conteúdo Representativo }\end{array} & \rightarrow \text { Objecto intencional } \\ \text { Intenção Sig. } \rightarrow & \text { Expressão } & \rightarrow \text { Referente }\end{array}$

Em suma: existe uma analogia entre a estrutura geral da Repräsentation e a da intencionalidade simbólica tal como aparece descrita na primeira das seis investigações lógicas. A questão que entretanto se coloca é esta: se a diferença entre o simbólico e o não simbólico deixa de poder ser feita com base numa diferença ao nível de Repräsentation (o que era específico da intencionalidade simbólica é válido para a estrutura global da Repräsentation), onde está então essa diferença?

De qualquer forma, pode concluir-se já que Husserl fez da indireccionalidade uma característica genérica, e não algo que é exclusivo das Repräsentationen simbólicas. Ora, mesmo correndo o risco de nos repetirmos, é importante insistir na ideia de que Husserl tinha procurado definir a oposição entre intencionalidade simbólica e intuitiva com base na tal diferença ao nível das Repräsentationen (a tal estrutura que é comum a todos os estados intencionais, mas que tinha um elemento diferenciador no caso das Rtn simbólicas - o elemento mediador - que nos permitia identificar fenomenologi- 
camente quando é que estávamos na presença de um ou de outro caso). Mas, tendo sido dissolvido o elemento diferenciador por força da generalização que o estendeu ao conjunto de todas as Repräsentationen, põe-se a questão de saber como pode essa oposição ser mantida. O problema assume aliás uma vertente dúplice: uma primeira dificuldade deriva, como dissemos, do facto de a propriedade distintiva da intencionalidade simbólica ter sido convertida numa propriedade genérica, pelo que deixou de poder contar como elemento diferenciador; mas a verdadeira dificuldade está na necessidade de reconciliar a indireccionalidade genérica da Repräsentation com o carácter directo da intencionalidade intuitiva. Como vemos, parece um dado incontornável o facto de a teoria husserliana se debater com a admissão de duas exigências (aparentemente) contraditórias. Perante isto, resta-nos apurar as formas de resolver o dilema.

Uma possibilidade seria mostrar que o próprio dilema é uma ilusão, enquanto que uma segunda estratégia passaria por rejeitar uma das duas exigências responsáveis pela sua emergência, isto é, ou Husserl abandona (b1) a "barreira eidética" que erigiu entre o simbólico e o intuitivo ou exclui (b2) a ideia segundo a qual a especificidade da intencionalidade intuitiva está na sua direccionalidade (e, mutatis mutandis, que a especificidade da intencionalidade simbólica está na sua indireccionalidade).

Ora, é impossível que Husserl renuncie à distinção entre estados intencionais, intuitivos e simbólicos (i.e., b1) sem virar do avesso toda a sua análise acerca do conhecimento ${ }^{13}$. Ciente disso, Husserl apresenta paulatinamente as coordenadas de uma estratégia que só no final do §26 da sexta investigação lógica se consubstancia em qualquer coisa de palpável e concreto. Relativamente à questão acerca do lugar onde podemos surpreender a diferença entre uma Repräsentation simbólica e uma não simbólica, e no âmbito dessa estratégia que referimos, há que distinguir claramente duas variantes: a primeira é uma questão acerca do conteúdo dessa diferença entre os dois tipos de Rtn, enquanto que a segunda é uma questão acerca da origem dessa diferença. E será justamente pela origem que Husserl aborda a questão.

Qual então a origem dessa diferença? Depois de rejeitar que ela esteja radicada na matéria do acto, Husserl faz derivar essa diferença dos respectivos conteúdos representativos. Para Husserl, o conteúdo representativo de uma Repräsentation intuitiva tem a propriedade especial da plenitude (Fülle), o que na terminologia husserliana equivale a dizer que se trata de um conteúdo representacional cujas determinações correspondem integralmente

13 Resta-nos então uma de duas possibilidades: ou mostramos que a situação dilémica entretanto criada é ilusória, o que não nos parece viável, dada a clareza dos termos em que o problema se coloca, ou então excluímos a ideia de que a especificidade da intencionalidade simbólica e intuitiva está respectivamente na sua indireccionalidade e na sua direccionalidade. 
às determinações do objecto intencional ${ }^{14}$ dessa Repräsentation à qual pertence (Husserl designará estes conteúdos representativos que tem a propriedade da plenitude "conteúdos puramente intuitivos"; Cf. \$23, sexta investigação lógica) ${ }^{15}$. No entanto, essa diferença não é ainda suficientemente esclarecedora. Restam-nos então duas alternativas: ou a diferença entre Repräsentation simbólica e não simbólica deve a sua origem à intersecção da Rtn com um elemento exterior a ela ou, pelo contrário, essa diferença nasce da união dos seus dois componentes (matéria/conteúdo representativo).

Husserl opta pela segunda alternativa, concedendo assim que a tão desejada diferença se determina ao nível das diversas formas como a matéria do acto interpreta ou apreende um conteúdo representativo. Isto significa ainda que, individualmente, o conteúdo representativo, bem como a matéria do acto, são neutros no que respeita à oposição entre o intuitivo e o simbólico. Husserl designará a propriedade de união entre a matéria do acto e o conteúdo representativo a forma de apreensão (Auffassungsform). Mas, tendo em consideração que a diferença entre a Rtn simbólica e intuitiva tem a sua origem na forma de apreensão do conteúdo representativo pela matéria do acto, o conteúdo dessa diferença só é perceptível na diferença correspondente entre a doação dos objectos intencionais. Isto significa que apreender um conteúdo representativo intuitivamente, por exemplo, é apreendê-lo de tal forma que o correlato intencional daí resultante seja considerado o próprio objecto, o que por sua vez equivale a dizer que o objecto é interpretado ou apreendido como estando presente (in propria persona).

Ora, que significa aqui esta noção de presença? ${ }^{16}$ Não deixa de ser tentador considerar que esta noção de presença é usada, neste contexto, com o objectivo de determinar que o objecto (esse que se considera apreendido como estando presente) é o termo directo ou imediato da relação intencional. Percebe-se facilmente que esta compreensão da presença do objecto (em que com ele se estabelece uma relação intencional que, sendo simbólica ${ }^{17}$, não

14 Isto é da vivência, quer dizer, do objecto estando a ser percebido.

15

Note-se ainda como esta correspondência denuncia claramente outro dos pontos mais característicos da fenomenologia husserliana, a saber, a ideia de que os elementos intencionais não são um componente real da vivência: "com efeito, seria de facto um contra-senso pretender que o predicado "vermelho" que convém, por exemplo, a uma superfície colorida, conviria igualmente à própria vivência perceptiva". Cf. PAISANA, João, Fenomenologia e Hermenêutica, Lisboa, Editorial Presença, pp. 47-51

16

No tipo perceptivo de uma intencionalidade intuitiva, o objecto percebido está presente desde logo no sentido temporal do termo. Ora, mas isto é próprio do tipo perceptivo da intencionalidade intuitiva, pelo que não vale como critério para definir a oposição ao nível do conjunto (e em que se afirmaria portanto como uma característica própria e essencial) da mesma intencionalidade intuitiva.

17

Vimos atrás que a característica que a primeira $I L$ havia considerada como sendo exclusiva da intencionalidade simbólica teria de ser admitida como uma propriedade genérica, e portanto, como algo que é comum a todos os estados intencionais (simbólicos e intuitivos). 
envolve a mediação de um símbolo), tenha dado um novo impulso à investigação da essência ou natureza dessa diferença entre intencionalidade simbólica e intuitiva. Convém acrescentar ainda que o estar presente ("em pessoa", como Husserl prefere dizer) já não pode ser visto em estrita oposição à presença mediada, uma vez que, como dissemos, Husserl reconhece a possibilidade de uma intencionalidade simbólica que não é mediada por um símbolo, enquanto assume simultaneamente que todo o tipo de relações intencionais se baseiam no papel mediador de um conteúdo representativo. Haverá contradição?

Na quinta investigação lógica, o autor determina finalmente o que é próprio da intencionalidade intuitiva: uma Repräsentation é de uma natureza intuitiva sempre que a matéria do respectivo acto apreenda o seu conteúdo representativo de tal forma que todas as determinações atribuídas ao objecto intemcional (por força do Auffassungssinn ${ }^{18}$ ) são consideradas como tendo um elemento correspondente no conteúdo representativo. Justamente por isso se dizia que o conteúdo representativo de uma Repräsentation devia ser pleno (Fülle), pois só assim permite que cada uma das suas determinações corresponda à determinação do objecto intencional.

Porém, a existência dessa correspondência não é ainda condição suficiente para distinguir a intencionalidade intuitiva na sua especificidade. É que essa correspondência entre as determinações do objecto intencional e as do conteúdo representativo devem ser reconhecidas. Por outras palavras, o seu conteúdo representativo completo (puro intuitivo) tem de ser apreendido como tal. Mas é precisamente sobre essa exigência suplementar de reconhecimento que Husserl irá cimentar a distinção entre Repräsentation simbólica e intuitiva. É que a característica mais "exclusiva" deste primeiro tipo de Repräsentation é justamente o facto de as determinações do respectivo conteúdo representativo não serem apreendidas como correspondentes às do objecto intencional. E porquê? A resposta a esta questão define precisamente a vantagem que o modo simbólico de intencionalidade tem sobre a intencionalidade intuitiva: é que a intencionalidade simbólica permite o estabelecimento de uma relação intencional com um objecto na base de qualquer conteúdo representativo (e não apenas daqueles conteúdos cujas determinações não só correspondem às do objecto intencional, mas que também são reconhecidas como tal). Portanto, enquanto que a relação entre as determinações do conteúdo representativo e as do objecto intencional têm de ser apreendidas como uma correspondência na intencionalidade intuitiva, essa relação é apreendida apenas como uma relação contingente e arbitrária no caso da intencionalidade simbólica. E é justamente nessa arbitrariedade que reside a sua característica verdadeiramente essencial.

18 Quer dizer, o sentido que a matéria do acto confere ao conteúdo representativo em virtude da apreensão que dele faz 
Ora, faltando o elemento da correspondência que é essencial para a $R e$ präsentation intuitiva, à $R$ tn simbólica falta também a base necessária que lhe permita apreender o objecto intencional como estando presente, isto é, como estando lá "em pessoa". E de facto assiste-se por parte de Husserl à assunção de que o objecto intencional de um estado intencional simbólico é apreendido como ausente. Mas, uma vez mais, a propriedade de "não estar em pessoa" que define a relação intencional simbólica com o objecto não pode ser definida como a propriedade de estar lá indirectamente, através de um substituto. Já não é esse o sentido de simbólico que tantos problemas nos causou $^{19}$. Agora, para que uma Repräsentation seja simbólica no sentido mais puro e geral do termo é suficiente que a matéria do acto não apreenda as determinações do conteúdo representativo como correspondentes às determinações do objecto intencional.

Esta nova forma de definir a linha divisória elimina claramente a noção de indireccionalidade da essência genérica da intencionalidade simbólica, e altera assim substancialmente as conclusões gerais da primeira investigação lógica. Efectivamente, num comentário revelador da sexta investigação lógica, Husserl admite expressamente que a dimensão simbólica de uma relação intencional não reside eo ipso no facto de ser mediada por um objecto, uma entidade intermediária e portanto simbólica, mas apenas no facto de ser mediada arbitrariamente, tanto mais que o símbolo não tem nada a ver com aquilo que lá está, já que justamente não existe correspondência entre as determinações do conteúdo representativo e as determinações do objecto intencional $^{20}$.

\section{Conclusão}

Estes desenvolvimentos mostram de uma forma clara e incontroversa que a teoria da intencionalidade de Husserl se debateu, desde o início, com as mesmas dificuldades que afligiram o fodorismo no seu projecto da reconstrução representacional do estado intencional: como pode uma concepção representacional da intencionalidade ser compatível com a distinção entre estados intencionais simbólicos e não-simbólicos, se por um lado esta distinção é equacionada como uma oposição entre um tipo directo e outro indirecto de intencionalidade, e se uma representação mental é imediatamente assimilada como um símbolo no sentido tradicional do termo, quer dizer, como um substituto para o objecto intencional?

\footnotetext{
19 Além disso, e como dissemos uma e outra vez ao longo desta apresentação, toda a relação intencional se baseia no papel mediador de um conteúdo representativo, pelo que é indirecta (simbólica) nesse sentido 
Todavia, a grande diferença entre os dois é que Husserl soube ter a disponibilidade necessária para analisar o problema por si mesmo, e foi essa disponibilidade que lhe permitiu tomar algumas decisões fundamentais, que agora recordamos:

$\mathbf{1}^{\mathbf{0}}$, altera a sua caracterização inicial da oposição entre intencionalidade simbólica e intuitiva dissociando-a da oposição entre intencionalidade directa e indirecta;

$2^{\circ}$, refaz essa oposição como uma diferença entre formas de apreensão (dos conteúdos representativos) arbitrárias ou contingentes e não-arbitrárias ou essenciais;

$\mathbf{3}^{\mathbf{0}}$, associa essa reconstrução a uma interpretação nova do contraste entre presença e ausência do objecto intencional.

Destas decisões, resulta a ideia de que toda a relação intencional é indirecta (porque inclui uma Repräsentation cujo conteúdo representativo é apreendido pela respectiva matéria); da mesma forma, considera-se que a estrutura genérica das Repräsentationen é indirecta no sentido em que envolve a mediação de um conteúdo representativo, embora - e é esta a novidade - essa indireccionalidade já não a impeça de ser intuitiva (pois toda a relação intencional envolve a mediação de um conteúdo representativo por forma estabelecer a relação intencional com o objecto). Aquilo que a indireccionalidade designa é o facto de apreendermos um objecto intencional como "ausente", mas essa ausência do objecto significa tão-só que as determinações do respectivo conteúdo representativo não têm de ser correspondentes com as determinações desse mesmo objecto intencional. A intencionalidade simbólica é pois aquela cuja relação a um objecto é mediada arbitrariamente por um conteúdo representativo a cujas determinações lhes falta o elemento de correspondência com as do próprio objecto intencional.

Se quisermos regressar à questão inaugural deste trabalho, podemos concluir que é de facto possível e legítimo um estudo criterioso da consciência, o que equivale a dizer que é possível estudar os fenómenos mentais sem os dissolver na sua essência. Isso faz pressupor no entanto algumas condições elementares, que aqui tivemos ocasião de sugerir. A estratégia que consiste em integrar a consciência e seus fenómenos em estruturas explicativas previamente delineadas está assim definitivamente ultrapassada. Não é possível explicar aquilo que não se conhece, da mesma forma que não é legítimo utilizar essa tentativa de compreensão como expediente para a prossecução de qualquer outro objectivo. De uma vez por todas, é necessário assegurar ao estudo da nossa vida mental a dignidade que lhe é devida. 


\begin{abstract}
One of the most significant marks of this article is the attempt to establish the idea that a new phenomenological approach is needed for the study consciousness and all it's features. The point is that the old demand for a scientific approach to consciousness shouldn't be, as it has been, incompatible with de need to preserve the essential nature of consciousness. Unfortunately, that's precisely the case in the majority of the proposals related with the study of consciousness. The debate with Fodor is thus quite important, since it brings to light precisely what one must avoid in order to save every single difficulty related with consciousness, and consciousness itself. A new methodology is therefore needed, one that is capable to observe the demands just acknowledged, but one that is capable to point new directions as well. Husserl, as we have seen, has much to say on the subject, but there is yet much to be done.
\end{abstract}

